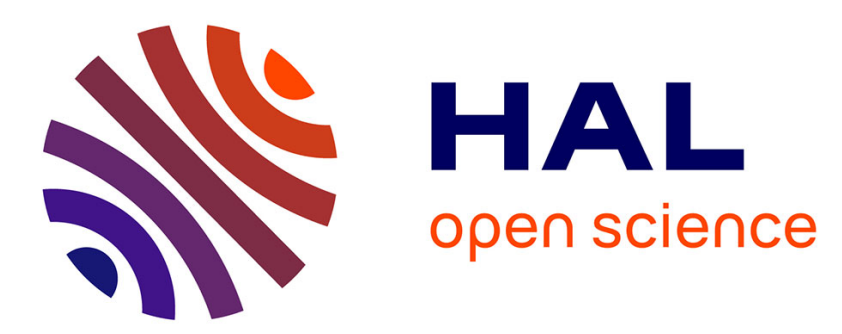

\title{
Burning velocities of hydrogen-methane-air mixtures at highly steam-diluted conditions
}

Göckeler Katharina, Eric Albin, Oliver Krüger, Christian Oliver Paschereit

\section{To cite this version:}

Göckeler Katharina, Eric Albin, Oliver Krüger, Christian Oliver Paschereit. Burning velocities of hydrogen-methane-air mixtures at highly steam-diluted conditions. 4th International Conference on Jets, Wakes and Separated Flows - ICJWSF-2013, Sep 2013, Nagoya, Japan. hal-00954523

\section{HAL Id: hal-00954523 \\ https://hal.science/hal-00954523}

Submitted on 22 Feb 2016

HAL is a multi-disciplinary open access archive for the deposit and dissemination of scientific research documents, whether they are published or not. The documents may come from teaching and research institutions in France or abroad, or from public or private research centers.
L'archive ouverte pluridisciplinaire HAL, est destinée au dépôt et à la diffusion de documents scientifiques de niveau recherche, publiés ou non, émanant des établissements d'enseignement et de recherche français ou étrangers, des laboratoires publics ou privés. 


\title{
BURNING VELOCITIES OF HYDROGEN-METHANE-AIR MIXTURES AT HIGHLY STEAM-DILUTED CONDITIONS
}

\author{
Katharina Göckeler ${ }^{1}$, Eric Albin ${ }^{2}$, Oliver Krüger ${ }^{1}$, and Christian Oliver Paschereit ${ }^{1}$ \\ ${ }^{1}$ Chair of Fluid Dynamics, Technische Universität Berlin \\ Müller-Breslau-Strasse 8, 10623 Berlin, Germany \\ katharina.goeckeler@tu-berlin.de \\ ${ }^{2}$ Université de Lyon, CNRS \\ Université de Lyon 1, F-69622, France \\ INSA-Lyon, CETHIL, UMR5008, F-69621, Villeurbanne, France
}

\begin{abstract}
Humidified gas turbines using steam generated from excess heat feature increased cycle efficiencies. Injecting the steam into the combustor reduces $\mathrm{NO}_{\mathrm{x}}$ emissions, flame temperatures and burning velocities, promising a clean and stable combustion of highly reactive fuels, such as hydrogen or hydrogen-methane blends. This study presents laminar burning velocities for methane, and hydrogen-enriched methane $(10 \mathrm{~mol} \%$ and $50 \mathrm{~mol} \%)$ at steam contents up to $30 \%$ of the air mass flow. Experiments were conducted on prismatic Bunsen flames stabilized on a slot-burner employing $\mathrm{OH}$ planar laserinduced fluorescence for determining the flame front areas. The experimental burning velocities agree well with results from one dimensional simulations using the GRI 3.0 mechanism. Burning velocities are increased with hydrogen enrichment, and reduce non-linearly with ascending steam molar fractions, showing the potential of steam dilution for a stable combustion of these fuels over a wide flammability range.
\end{abstract}

\section{INTRODUCTION}

In gas turbines, excess heat can be effectively recovered to generate steam. Injecting the steam into the combustor leads to a higher cycle efficiency and reduces the formation of $\mathrm{NO}_{\mathrm{x}}$ emissions, meeting modern demands of power generation [1]. For the influence of steam on the combustion process, three mechanisms have been identified: (1) a dilution effect reducing the molar fraction of total reactive species, (2) a thermal effect due to an increased specific heat capacity, and (3) a chemical influence on kinetic reactions often related to its high efficiency in third-body reactions $[2,3,4,5,6]$. As a result, flame temperatures and burning velocities are reduced, lowering the risk of flashback. Therefore, wet cycles represent a promising technique for the clean and stable combustion of highly reactive fuels, such as hydrogenenriched fuels and pure hydrogen.

The laminar burning velocity is a fundamental parameter for the assessment of the combustor operability and the validation of kinetic mechanisms. Measurements are mainly conducted on either propagating flames or stationary Bunsen flames [7]. The flame propagation methods require a correction for flame stretch and curvature effects, but yield consistent results, if these correlations are known [8]. The stationary flame method is regarded as the less complex configuration, and is used in the present study. It is based on the extraction of flame surface areas from flame images. An error source for this method are stretch and curvature effects at the flame tip and the flame shoulder near the burner nozzle. Selle et al. [9] compared measurements on a prismatic Bunsen flame similar to the present setup with Direct Numerical Simulations, and quantified the influence of these effects to only $1 \%$. However, they postulated that the error may increase for mixtures exhibiting Lewis numbers far from unity.

For methane-air mixtures several studies on laminar burning velocities are available [10, 11, 12, 13], whereas investigations of steam-diluted mixtures are more scarce, and often limited to comparably low water vapor contents $[2,9,14]$ or to stoichiometric methane-air-steam mixtures [15, 4, 8]. Selle et al. [9] and Boushaki et al. [14] conducted experiments on a prismatic Bunsen flame for water vapor contents up to the saturation point in air. Mazas et al. [4] studied methane-air-steam mixtures for molar steam fractions up to $15 \mathrm{~mol} \%$, and used oxygen-enriched mixtures to achieve higher steam contents of $45 \mathrm{~mol} \%$. They found a quasi-linear decrease in burning velocity with steam molar fraction. Galmiche et al. [8] extracted burning velocitites from spherically expanding flames for steam molar fractions up to $25 \mathrm{~mol} \%$ of the stoichiometric mixture at preheat temperatures of $470 \mathrm{~K}$. Their results showed some deviations from a linear decrease, which they related to a small, but negligible chemical effect of steam. Recently, Albin et al. [16] measured burning velocities over a wider equivalence ratio range and steam molar fractions up to $25 \mathrm{~mol} \%$ at preheat temperatures of $480 \mathrm{~K}$ using a prismatic Bunsen flame and a turbulent rod-stabilized V-flame. The reduction in burning velocity with steam molar fraction was akin for the laminar and turbulent flame.

The influence of hydrogen addition on methaneair combustion found some interest in the past decade $[17,18,19,20,14]$. Wang et al. [19] showed that the 


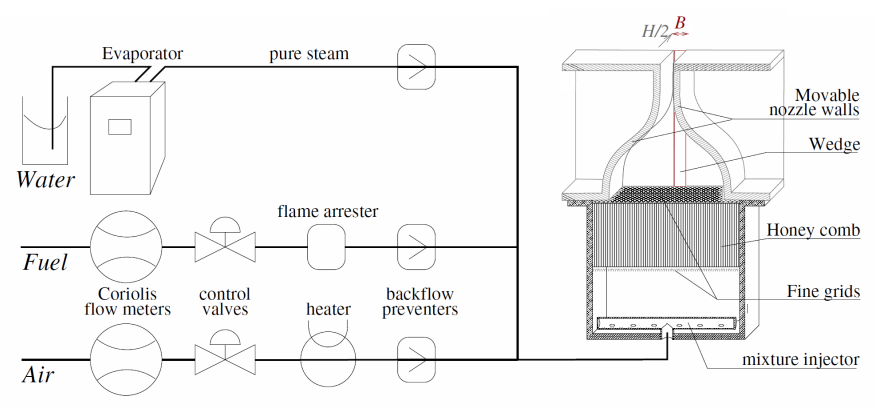

(a) Schematic of slot-burner
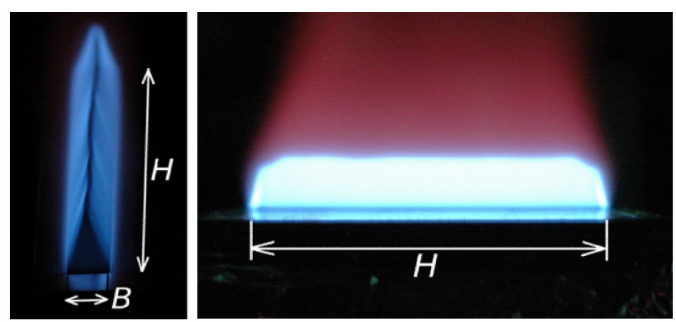

(b) Flame images

Figure 1: Experimental setup: (a) schematic of slot burner including flow supplies, and (b) photos of the flame from front-top view (left) and side view (right).

promotion of chemical reaction with hydrogen addition is due to the increase of $\mathrm{H}, \mathrm{O}$ and $\mathrm{OH}$ mole fractions in the flame as hydrogen is added. Boushaki et al. [14] conducted experiments on a slot burner for molar fractions of hydrogen between $0 \mathrm{~mol} \%$ and $30 \mathrm{~mol} \%$ for different pressures and inlet temperatures. They showed that the enrichment of fuel with hydrogen increases burning velocity linearly.

The current study extends the existing database by showing the combined effect of hydrogen enrichment and steam dilution of methane-air mixtures. Hydrogen contents in fuel of $0 \mathrm{~mol} \%, 10 \mathrm{~mol} \%$, and $50 \mathrm{~mol} \%$ are studied for an increasing dilution with steam up to $0.29 \mathrm{~mol} \%$ of the gas mixture. The experiments were conducted on an atmospheric prismatic Bunsen flame stabilized on a slotburner at a fixed preheat temperature of $440 \mathrm{~K}$. Flame areas are extracted from $\mathrm{OH}$ planar laser-induced fluorescence (OH-PLIF). Additionally, flow velocities are obtained from Particle Image Velocitmetry (PIV) for some of the investigated operating conditions. The experimental results are compared to one dimensional simulations, which were performed using the GRI 3.0 mechanism of Smith et al. [21].

In the following, the experimental setup and the investigated operating conditions are specified, and the post processing method for the extraction of flame front areas from the OH-PLIF images illustrated. Thereafter, the flow field of the Bunsen flame, the flame structure and burning velocities of the various mixtures are presented and discussed.

\section{EXPERIMENTAL SETUP}

Experiments were conducted on an atmospheric prismatic Bunsen flame stabilized on a rectangular slotburner. A schematic illustrates both the test-rig and the supply lines of steam, fuel, and air (Fig. 1). A honeycomb and a fine grid, placed in the settling chamber upstream of the nozzle, were used to homogenize and laminarize the flow. The slot outlet area sizes $B \times H=10 \times 100 \mathrm{~mm}^{2}$. More details on the nozzle shape are available in Albin et al. [16]. For the present study, the nozzle mouth was extended in length in order to damp acoustically introduced oscillations of the flame [9].

The mass flow rates of methane and air were controlled by Coriolis mass flow meters, and two pneumatically driven control valves. The air was heated with a $1.5 \mathrm{~kW}$ preheater, and an evaporator of $3 \mathrm{~kW}$, equipped with a pressure based flow meter $( \pm 10 \%)$, was used to generate steam. The preheated air and steam were premixed with the fuel upstream of the burner. In order to reduce heat losses, the supply lines, as well as the burner were insulated with ceramic fibres. The temperature of the mixture was monitored by a thermocouple positioned $95 \mathrm{~mm}$ upstream of the nozzle outlet without perturbing the flame. A second thermocouple was used beforehand to check for deviations to the temperature at the actual nozzle outlet. For all investigated operating conditions a fixed preheat temperature of $440 \mathrm{~K}$ was used.

The steam content $\Omega$ is given as mass fraction of steam to air:

$$
\Omega=\frac{\dot{m}_{\text {steam }}}{\dot{m}_{\text {air }}}
$$

The enrichment with hydrogen is characterized by the molar fraction of hydrogen in fuel $X_{\mathrm{H} 2}$ :

$$
X_{\mathrm{H} 2}=\frac{\mathrm{n}\left(\mathrm{H}_{2}\right)}{\mathrm{n}\left(\mathrm{H}_{2}+\mathrm{CH}_{4}\right)}
$$

with $n$ referring to the molar amount of substance.

The equivalence ratio describes the mass fraction of fuel in oxidizer normalized with the stoichiometric ratio. It is derived from the global one-step reaction for the oxidation of hydrogen-methane mixtures [20]:

$$
\mathrm{CH}_{4}+\mathrm{H}_{2}+2.5 \mathrm{O}_{2} \rightarrow \mathrm{CO}_{2}+3 \mathrm{H}_{2} \mathrm{O}
$$

which yields the equivalence ratio $\phi$ based on mass fractions $Y$ :

$$
\phi=\frac{\dot{m}_{\text {fuel }}\left(4 Y_{\text {fuel }}^{\mathrm{CH} 4}+8 Y_{\text {fuel }}^{\mathrm{H} 2}\right)}{\dot{m}_{\text {air }} Y_{\text {air }}^{\mathrm{O} 2}}
$$

An overview over the investigated operating conditions is provided in Tab. 1 . The bulk velocity of unburnt gases $U_{u}$ was varied in order to maintain a stable flame at different burning velocities $S_{l}$. For an increasing enrichment with hydrogen, higher bulk velocities relative to 
Table 1: Investigated operating conditions characterized by the molar fraction of hydrogen in fuel $X_{\mathrm{H} 2}$, the mass fraction of steam in air $\Omega$, the equivalence ratio $\phi$, the bulk velocity of the unburnt gases $U_{u}$, and its ratio to the laminar burning velocity $S_{l}$. The preheat temperature is kept constant at $440 \mathrm{~K}$.

\begin{tabular}{ccccc}
\hline $\begin{array}{c}X_{\mathrm{H} 2} \\
-\end{array}$ & $\Omega$ & $\phi$ & $\begin{array}{c}U_{u} \\
(\mathrm{~m} / \mathrm{s})\end{array}$ & $\begin{array}{c}S_{l} / U_{u} \\
\%\end{array}$ \\
\hline 0 & $0-0.15$ & $0.8-1.3$ & $1.3-2.4$ & $14-34$ \\
0.1 & $0-0.20$ & $0.7-1.3$ & $1.2-2.6$ & $14-33$ \\
0.5 & $0-0.30$ & $0.6-1.3$ & $1.1-6.3$ & $10-22$ \\
\hline
\end{tabular}

the burning velocity were needed due to a more frequent occurrence of flashback. The highest steam content of $\Omega=0.30$ was reached for the highest enrichment with hydrogen tested.

Laminar burning velocities are extracted from measurements of $\mathrm{OH}$ planar laser-induced fluorescence $(\mathrm{OH}-$ PLIF). A dye laser operated with Rhodamine 6G and pumped with a Nd:YAG laser was used at an energy of $8 \mathrm{~mJ}$ per pulse and a wavelength of around $283 \mathrm{~nm}$ for triggering the fluorescence. The laser sheet was positioned at the slot length center $H / 2$. An image intensified camera, equipped with a band pass filter centered at $308 \mathrm{~nm}$, was positioned perpendicular to the laser sheet. For each case, a series of 100 images was recorded at a frequency of $5 \mathrm{~Hz}$ and an image resolution of $14 \mathrm{px} / \mathrm{mm}$.

Additionally, flow velocities were measured for some of the investigated cases by employing Particle Image Velocitmetry (PIV) with a Nd:YAG laser of $532 \mathrm{~nm}$ outlet wavelength. The PIV images of $36 \mathrm{px} / \mathrm{mm}$ resolution were processed with a final interrogation area of $24 \times 24 \mathrm{px}^{2}$ with $50 \%$ overlap. A brush-based powder disperser provided a homogeneous distribution of titanium dioxide seeding.

\section{FLAME FRONT DETECTION}

The burning velocity is defined as the relative velocity of unburnt gases normal to the flame front as they move into the flame [7]. For stationary flames, this is equal in amount to the flame propagation velocity into the unburnt mixture. Following the continuity equation, burning velocities $S_{l}$ of laminar Bunsen flames are calculated from the mass flow of unburnt gases $\dot{m}_{\mathrm{u}}$, their density $\rho_{\mathrm{u}}$, and the flame front area $A_{f}$ :

$$
S_{l}=\frac{\dot{m}_{\mathrm{u}}}{\rho_{\mathrm{u}} A_{f}}
$$

The area of the flame $A_{f}$ is obtained from the two dimensional flame length $L_{f}$ in the measurement plane multiplied with the slot length $H$, thus assuming a prismatic flame shape:

$$
A_{f}=L_{f} H
$$

However, the flame shape is not entirely prismatic (Fig. 1b) due to wall-boundary effects at the slot extrem-

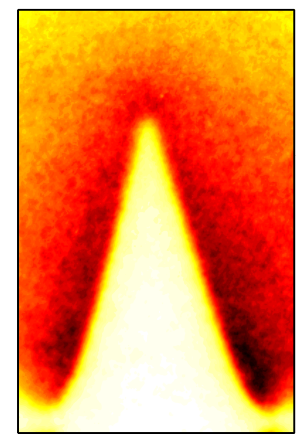

(a) POD image

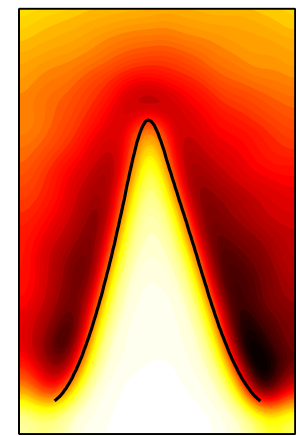

(b) Filtered image and spline
Figure 2: Different stages of data post processing: (a) first POD mode of OH-PLIF image series, and (b) spatially filtered POD image with fitted spline at flame front.

ities, which increase flow velocities at the measurement plane in the slot center. Selle et al. [9] quantified the flow acceleration, and suggested to use a correction factor of 1.054 for the present slot dimensions.

The two dimensional flame length $L_{f}$ is determined from the measured OH-PLIF images. The $\mathrm{OH}$ radical is an intermediate combustion product, and well accepted as an indicator for heat release. An edge detection algorithm based on the Canny method is used to detect the maximum gradient of the $\mathrm{OH}$ signal. In order to reduce the influence of noise and to correct for slight movements of the flame, the first mode of the proper orthogonal decomposition of the time series of OH-PLIF images is used. Further improvement of the reliability of the edge detection was achieved by means of a moving average (100 times $3 \times 3 \mathrm{px}^{2}$ ), which reduces local gradients within the unburnt and burnt regions. Figure 2 shows an example of a POD image (Fig. 2a) and the corresponding spatially filtered image (Fig. 2b).

The identified image points describing the flame front are fitted with a spline $s(x)$ by means of a least square error method. Figure $2 \mathrm{~b}$ shows exemplary a filtered POD image together with the computed spline. The flame length $L_{f}$ is then calculated from the line integral between the left and right flame base, according to [16]:

$$
L_{f}=\int \sqrt{1+(d s(x) / d x)^{2}} d x
$$

A shortcoming of this technique is that the flame base is not clearly detectable on the OH-PLIF images, as the $\mathrm{OH}$ signal spreads radially creating a gradient near the nozzle exit between the quenching distance and $\mathrm{OH}$ detected in the post flame zone. Therefore, the spline was computed only between the left and right longitudinal minimum of the $\mathrm{OH}$ distribution. This method might introduce uncertainties into the flame front detection process. Nevertheless, it is believed that the flame surface technique is superior to angle based methods, which assume a perfectly triangular flame shape. A comparison of both methods is available in Selle et al. [9]. 


\section{RESULTS}

\subsection{Time averaged flow field}

For some of the investigated cases the flow field was measured in order to review the level of velocity fluctuations in the Bunsen flame. A time averaged flow field is exemplary presented in Fig. 3. The streamlines show the purely axial direction of the flow for the unburnt gases. The flame is stabilized at the slot-nozzle exit leading to a prismatic flame front, which accelerates the flow both in axial and lateral directions. Additionally, Fig. 3 presents the local turbulence intensity $I^{*}$ calculated from the time averaged axial and lateral velocity fluctuations, $u^{\prime}$ and $v^{\prime}$, respectively:

$$
I^{*}=\sqrt{\frac{1}{2}\left(\overline{u^{\prime 2}}+\overline{v^{\prime 2}}\right)} / \bar{u}
$$

The fluctuations are normalized with the local, time averaged axial velocity $\bar{u}$.

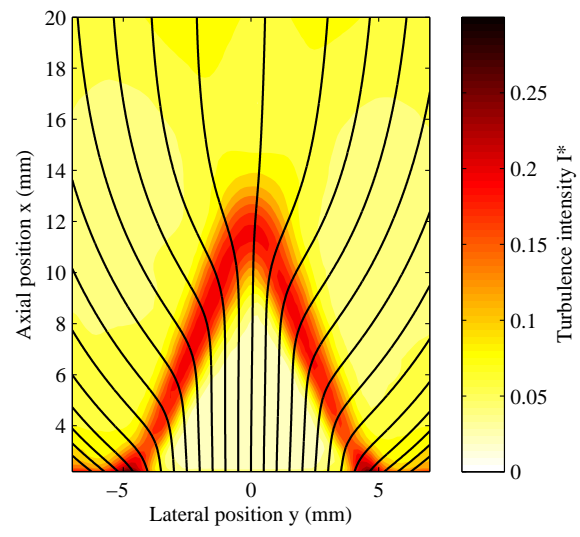

Figure 3: Local turbulence intensity $I^{*}$ overlayed with streamlines of the time averaged flow $\left(X_{\mathrm{H} 2}=10 \%, \Omega=\right.$ $0.1, \phi=1.1)$.

For the unburnt gases, the turbulence intensity is found to be below $I^{*} \leq 5 \%$. The highest turbulence intensity is encountered in the periphery of the flame front due to some fluctuations in flame position. Aerodynamic shear with the surrounding quiescent air, enhanced by lateral density gradients, leads to entrainment of air into the flame, and a slight movement of the flame front. However, the basic structure of the flame remains consistent for all instantaneous images, and no wrinkling of the flame front was observed, which justifies an extraction of laminar burning velocities from the POD based averaged images.

\subsection{Flame shape}

This section briefly addresses the influence of a dilution with steam on the flame shape. In Fig. 4, the steam content is increased from left to right between $\Omega=0$ and $\Omega=0.2$. The steam-diluted flame is more distributed resulting in a less distinguishable edge at the flame front compared to the dry flame potentially stemming from less steep gradients in $\mathrm{OH}$ production [6]. Moreover, the diluted flame is slightly lifted, and, here, only similar

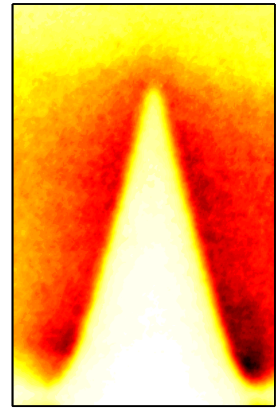

(a) $\Omega=0, U_{u}=2.6 \mathrm{~m} / \mathrm{s}$

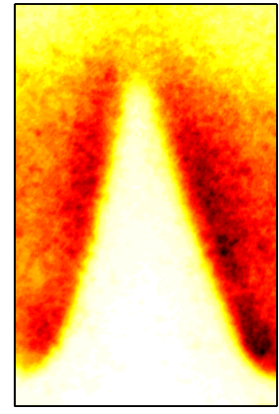

(b) $\Omega=0.2, U_{u}=1.2 \mathrm{~m} / \mathrm{s}$
Figure 4: Qualitative $\mathrm{OH}$ distributions for increasing steam contents $\Omega\left(X_{\mathrm{H} 2}=10 \%, \phi=1\right)$. The signal resolution is different for each image.

in length, as the bulk velocity is three times lower. A constant bulk velocity would lead to a flame elongation at diluted conditions. These observations are consistent with results reported in previous works for a turbulent flame [22].

\subsection{Laminar burning velocities}

The experimentally determined burning velocities are compared with one dimensional simulations using the GRI 3.0 mechanism of Smith et al. [21] including 325 elementary reactions and 53 species. The results are presented in Fig. 5. The experiments are conducted for equivalence ratios reaching from fuel-rich mixtures till the lean blow out limit. In the majority of the cases, a decent agreement between experimental and simulated burning velocities is achieved, suggesting that the GRI 3.0 mechanism is well suited to predict hydrogenmethane-air-steam mixtures of varying composition. Individual outliers are mostly found for high steam mass flows, which are present for high steam contents $\Omega$, but also for high bulk velocities needed to stabilize the $50 \mathrm{~mol} \%$-hydrogen flames. These deviations might be related to some extend to the comparably high uncertainty of the pressure based mass flow meter installed in the evaporator. Also, the flame becomes increasingly more distributed for ascending steam contents (Fig. 4), which might affect the edge detection method. In average, the deviation for all investigated cases amounts to $4 \%$ only. The reproducibility of systematically repeated operating conditions is $5 \%$ in average.

An enrichment with hydrogen by $50 \%$ in molar fraction leads to a strong increase in burning velocity by a factor of around 1.6 (Fig. 5a-5c), extending the flammability range to lower equivalence ratios. At the same time, the maximum of burning velocity of approximately $\phi=1.05$ for methane-air is slightly shifted towards a higher equivalence ratio of about $\phi=1.1$. A dilution with steam reduces laminar burning velocities for all investigated mixtures. For the methane-air-steam flame, a dilution with steam of only $10 \%$ of the air mass flow reduces the maximum burning velocity by almost a half. The highest steam content of $\Omega=0.3$ is reached for 


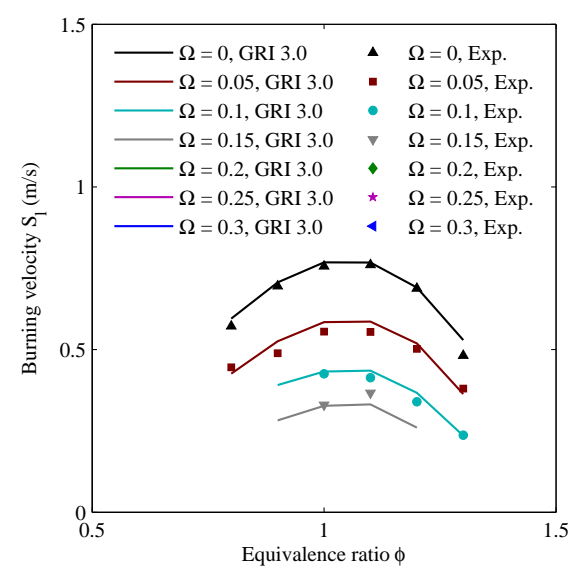

(a) $X_{\mathrm{H} 2}=0$

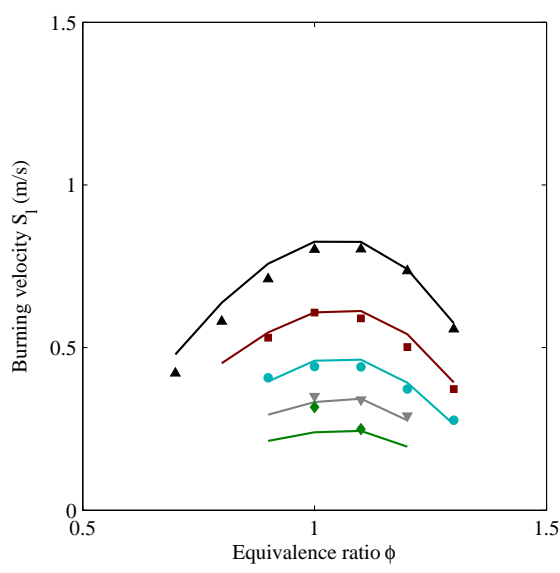

(b) $X_{\mathrm{H} 2}=0.1$

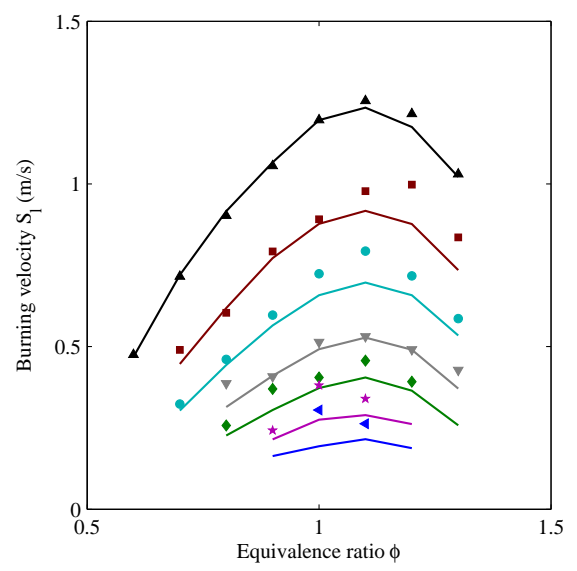

(c) $X_{\mathrm{H} 2}=0.5$

Figure 5: Laminar burning velocities for varying H2-CH4-air-steam mixtures extracted from prismatic Bunsen flame experiments and simulated using GRI 3.0 mechanism [21]. The preheat temperature was kept at $440 \mathrm{~K}$. The legends for (b) and (c) are identical to (a).

a hydrogen content of $50 \%$ of fuel (Fig. 5c). Compared to dry conditions, the burning velocity is reduced by around $85 \%$. The distribution of burning velocities for steam-diluted hydrogen-enriched flames are comparable to those of methane-air flames, but feature a wider flammability range, which shows the potential of steam dilution for the stable combustion of hydrogen-enriched methane.

The decrease in burning velocity $S_{l}$ with the steam molar fraction $X_{\mathrm{H} 2 \mathrm{O}}$ of the stoichiometric gas mixture is presented in Fig. 6. Here, the steam molar fraction is used, since it represents the most common quantity for characterizing diluent contents. Normalization with the burning velocity at dry conditions $S_{l}(\Omega=0)$ allows for a comparison with previous experiments conducted at different preheat temperatures. For the present study, the simulated data are shown, as the experimental results exhibit some outliers around the stoichiometry. The simulated curves agree closely with data presented in Galmiche et al. [8], and approximately coincide, suggesting that for the investigated range the reduction in burning velocity with steam molar fraction is relatively independent of the level of hydrogen enrichment.

For lower steam contents of less than $X_{\mathrm{H} 2 \mathrm{O}} \leq 0.15$, the decrease in burning velocity seems quasi-linear, as pointed out by other authors [4, 14]. However, for higher steam contents, which are reached in the present study by an enrichment with hydrogen, a significant deviation from a linear decrease becomes evident, which is shown in Fig. 6 by fitting a straight line to the burning velocities at lower steam contents. A correction with the thermal diffusivity as proposed by Koroll and Mulpuru [3] leads to a similar slope of the curves, which suggests that the influence of steam is not purely thermal by altering the thermal diffusivity, but that the steam contributes to the reaction mechanisms. Further simulations are needed to assess the influence on individual reaction steps of methane-hydrogen combustion, and to quantify this chemical influence depending on steam content.

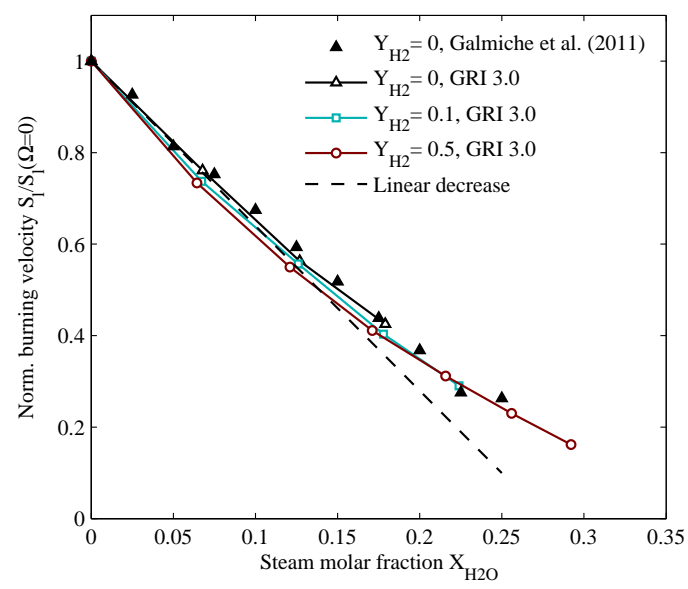

Figure 6: Normalized burning velocities $S_{l} / S_{l}(\Omega=0)$ over steam molar fraction, where $S_{l}(\Omega=0)$ refers to the burning velocity of the dry mixture $(\phi=1)$.

\section{CONCLUSIONS}

The combined influence of steam dilution and hydrogen enrichment on the laminar burning velocity of methaneair mixtures was studied. Experiments were conducted on an atmospheric Bunsen flame stabilized on a slotburner. The flame front areas needed to determine burning velocities were extracted from $\mathrm{OH}$ planar laserinduced fluorescence. The experimental data was used to validate one dimensional simulations employing the GRI 3.0 mechanism.

An enrichment with hydrogen significantly increased the laminar burning velocity extending the flammable range towards leaner conditions. A dilution with steam reduced burning velocities similarly for the tested levels of hydrogen addition. The increased burning velocities for hydrogen-enriched methane enabled a dilution with steam of $29 \mathrm{~mol} \%$ of the gas mixture. At these high steam contents, the decrease in burning velocity with steam molar fraction deviates significantly from the linear behavior often found for lower steam contents. 


\section{ACKNOWLEDGEMENTS}

The authors would like to thank Simon Kern, Andy Göhrs, and Holger Nawroth for their valuable contributions during the conduction and preparations of the experiments.

The research leading to these results has received funding from the European Research Council under the ERC grant agreement no. 247322, GREENEST.

\section{References}

[1] M. Jonsson and J. Yan, "Humidified gas turbines-a review of proposed and implemented cycles," Energy, vol. 30, pp. 1013-1078, June 2005.

[2] V. Babkin and A. V'yun, "Effect of water vapor on the normal burning velocity of a methane-air mixture at high pressures," Combustion, Explosion, and Shock Waves, vol. 7, no. 3, pp. 339-341, 1971.

[3] G. W. Koroll and S. R. Mulpuru, "The effect of dilution with steam on the burning velocity and structure of premixed hydrogen flames," Symposium (International) on Combustion, vol. 21, no. 1, pp. 1811-1819, 1988.

[4] A. Mazas, B. Fiorina, D. Lacoste, and T. Schuller, "Effects of water vapor addition on the laminar burning velocity of oxygen-enriched methane flames," Combustion and Flame, vol. 158, pp. 24282440, Dec. 2011.

[5] S. Göke and C. O. Paschereit, "Influence of Steam Dilution on Nitrogen Oxide Formation in Premixed Methane/Hydrogen Flames," Journal of Propulsion and Power, Jan. 2012.

[6] O. Krüger, "Large Eddy Simulations of Hydrogen Oxidation at Ultra-Wet Conditions in a Model Gas Turbine Combustor Applying Detailed Chemistry," Journal of Engineering for Gas Turbines and Power, vol. 135, p. 021501, Jan. 2013.

[7] C. Rallis and A. Garforth, "The determination of laminar burning velocity," Progress in Energy and Combustion Science, vol. 6, no. 4, pp. 303-329, 1980.

[8] B. Galmiche, F. Halter, F. Foucher, and P. Dagaut, "Effects of Dilution on Laminar Burning Velocity of Premixed Methane/Air Flames," Energy $\&$ Fuels, vol. 25, pp. 948-954, Mar. 2011.

[9] L. Selle, T. Poinsot, and B. Ferret, "Experimental and numerical study of the accuracy of flame-speed measurements for methane/air combustion in a slot burner," Combustion and Flame, vol. 158, pp. 146154, Jan. 2011.

[10] C. M. Vagelopoulos and F. N. Egolfopoulos, "Direct experimental determination of laminar flame speeds," Proceedings of the Combustion Institute, vol. 27, no. 1, pp. 513-519, 1998.

[11] X. Gu, M. Haq, M. Lawes, and R. Woolley, "Laminar burning velocity and Markstein lengths of methane-air mixtures," Combustion and Flame, vol. 121, no. 1-2, pp. 41-58, 2000.
[12] G. Rozenchan, D. Zhu, C. Law, and S. Tse, "Outward propagation, burning velocities, and chemical effects of methane flames up to 60atm," Combustion and Flame, vol. 29, no. 2, pp. 1461-1470, 2002.

[13] K. J. Bosschaart and L. P. H. D. Goey, "The laminar burning velocity of flames propagating in mixtures of hydrocarbons and air measured with the heat flux method," Combustion and Flame, vol. 136, pp. 261269, 2004.

[14] T. Boushaki, Y. Dhué, L. Selle, B. Ferret, and T. Poinsot, "Effects of hydrogen and steam addition on laminar burning velocity of methane-air premixed flame: Experimental and numerical analysis," International Journal of Hydrogen Energy, vol. 33, pp. 1-11, Apr. 2012.

[15] T. Le Cong and P. Dagaut, "Experimental and Detailed Modeling Study of the Effect of Water Vapor on the Kinetics of Combustion of Hydrogen and Natural Gas, Impact on NOx," Energy \& Fuels, vol. 23, pp. 725-734, Feb. 2009.

[16] E. Albin, H. Nawroth, S. Göke, Y. D'Angelo, and C. O. Paschereit, "Experimental investigation of burning velocities of ultra-wet methane-air-steam mixtures," Fuel Processing Technology, Aug. 2012.

[17] F. Halter, C. Chauveau, N. Djebaïli-Chaumeix, and I. Gökalp, "Characterization of the effects of pressure and hydrogen concentration on laminar burning velocities of methane-hydrogen-air mixtures," Proceedings of the Combustion Institute, vol. 30, pp. 201-208, Jan. 2005.

[18] M. Ilbas, A. Crayford, I. Yilmaz, P. Bowen, and N. Syred, "Laminar-burning velocities of hydrogen-air and hydrogen-methane-air mixtures: An experimental study," International Journal of Hydrogen Energy, vol. 31, pp. 1768-1779, Sept. 2006.

[19] J. Wang, Z. Huang, C. Tang, H. Miao, and X. Wang, "Numerical study of the effect of hydrogen addition on methane-air mixtures combustion," International Journal of Hydrogen Energy, vol. 34, pp. 1084-1096, Jan. 2009.

[20] S. Bougrine, S. Richard, A. Nicolle, and D. Veynante, "Numerical study of laminar flame properties of diluted methane-hydrogen-air flames at high pressure and temperature using detailed chemistry," International Journal of Hydrogen Energy, vol. 36, pp. 12035-12047, Sept. 2011.

[21] G. P. Smith, D. M. Golden, M. Frenklach, N. W. Moriarty, B. Eiteneer, M. Goldenberg, C. T. Bowman, R. K. Hanson, S. Song, W. C. J. Gardiner, V. V. Lissianski, and Z. Qin, GRI 3.0. http://www.me.berkeley.edu/gri_mech/, 2000.

[22] S. Göke, S. Terhaar, S. Schimek, K. Göckeler, and C. O. Paschereit, "Combustion of natural gas, hydrogen and bio-fuels at ultra-wet conditions," in Proceedings of the ASME Turbo Expo 2011, June 6-10, 2011, Vancouver, Canada, 2011. 